\title{
Exocrine and Endocrine Pancreatic Cancer pM1 TNM Finding v7
}

National Cancer Institute

\section{Source}

National Cancer Institute. Exocrine and Endocrine Pancreatic Cancer pM1 TNM Finding

v7. NCl Thesaurus. Code C90300.

Exocrine or endocrine pancreatic cancer with distant metastasis. (from AJCC 7th Ed.) 